\title{
Prediction of the Grade of Acute Cholecystitis by Plasma Level of C-Reactive Protein
}

\author{
Esin Kabul Gurbulak ${ }^{1, *}$; Bunyamin Gurbulak ${ }^{2}$; Ismail Ethem Akgun ${ }^{1}$; Yigit Duzkoylu ${ }^{3}$; \\ Muharrem Battal ${ }^{1}$; Mustafa Fevzi Celayir ${ }^{1}$; Uygar Demir ${ }^{1}$ \\ ${ }^{1}$ Department of General Surgery, Sisli Hamidiye Etfal Training and Research Hospital, Istanbul, Turkey \\ 2 Department of General Surgery, Arnavutkoy State Hospital, Istanbul, Turkey \\ ${ }^{3}$ Department of General Surgery, Istanbul Training and Research Hospital, Istanbul, Turkey \\ ${ }^{*}$ Corresponding Author: Esin Kabul Gurbulak, Department of General Surgery, Sisli Hamidiye Etfal Training and Research Hospital, Istanbul, Turkey. Tel: +90-2123736146, \\ Fax:+90-2122240772, E-mail: ekabul@gmail.com
}

Received: February 19, 2015; Revised: March 9, 2015; Accepted: March 24, 2015

\begin{abstract}
Background: Acute cholecystitis is the most common complication of gallbladder stones. Today, Tokyo guidelines criteria are recommended for diagnosis, grading, and management of acute cholecystitis.

Objectives: We aimed to evaluate the levels of C-reactive protein (CRP) at different cut-off values to predict the severity of the disease and its possible role in grading the disease with regard to the guideline.

Patients and Methods: This is a retrospective study, analyzing 682 cases out of consecutive 892 patients with acute cholecystitis admitted to two different general surgery clinics in Istanbul, Turkey. Records of patients diagnosed with acute cholecystitis were screened retrospectively from the hospital computer database between January 2011 and July 2014. A total of 210 patients with concomitant diseases causing high CRP levels were excluded from the study. The criteria of Tokyo guidelines were used in grading the severity of acute cholecystitis, and patients were divided into 3 groups. CRP values at the time of admission were analyzed and compared among the groups. Results: Mean CRP levels of groups were found to be significantly different, $18.96 \mathrm{mg} / \mathrm{L}$ in Group I, $133.51 \mathrm{mg} / \mathrm{L}$ in Group II, and $237.23 \mathrm{mg} / \mathrm{L}$ in Group III $(\mathrm{P}<0.001)$. Having examined CRP values among the groups, they were found to be highly and significantly correlated with the disease grade $(\mathrm{P}<0.0001)$. After evaluating CRP levels according to the grade of the disease, group 2 was distinguished from group 1 with a cut-off CRP level of $70.65 \mathrm{mg} / \mathrm{L}$, and from group 3 with a value of $198.95 \mathrm{mg} / \mathrm{L}$. Those results were found to be statistically significant $(\mathrm{P}<0.001)$.

Conclusions: CRP, a well-known acute phase reactant that increases rapidly in various inflammatory processes, can be accepted as a strong predictor in classifying different grades of the disease, and treatment can be reliably planned according to this classification.
\end{abstract}

Keywords: Acute Cholecystitis; C Reactive Protein; Cholecystectomy

\section{Background}

Acute cholecystitis is the most common complication of gallbladder stones, and one of the most frequently seen acute surgical diseases (1). Before Tokyo guidelines, there was not a consensus over diagnosis and evaluation of acute cholecystitis. Management strategy of acute cholecystitis was introduced for effective dissemination of the guidelines in the world $(2,3)$. Today, Tokyo guidelines criteria are recommended for the diagnosis of acute cholecystitis, since it standardizes the treatment approach by staging the severity of the disease (4, 5 ). According to these guidelines, diagnostic criteria for acute cholecystitis include physical examination findings, laboratory results such as C-reactive protein (CRP) and white blood cell levels, as well as radiologic evaluation. Following the diagnosis, clinical severity of the disease is defined and assigned to 1 of the 3 grades based on Tokyo guidelines, which observes various clinical findings, including patient's history (duration of symp- toms), physical examination, laboratory tests, and imaging methods $(4,5)$. CRP level is only used as a diagnostic criterion of acute cholecystitis, and it is not part of the determinant criteria of the severity assessment of the disease in the guideline. On the other hand, correlation between CRP levels and severity of acute cholecystitis is a well-known fact, and several studies have reported that CRP level is a reliable predictor of severe conditions of the inflammation in acute cholecystitis (6-13). But a cut-off level of CRP that reveals the grade of the disease has not been proposed so far.

\section{Objectives}

Considering the relationship between CRP levels and grade of inflammation, we investigated the levels of CRP at different cut-off levels to predict the severity of the disease and its possible role in grading the disease according to Tokyo guideline for our patients. 


\section{Patients and Methods}

The study is based on the retrospective analysis of 682 cases out of consecutive 892 patients with acute cholecystitis admitted to 2 different centers: Sisli Etfal Training and Research Hospital, and Arnavutkoy State Hospital, General Surgery Clinics, in Istanbul, Turkey. Patients admitted to the hospital diagnosed with acute cholecystitis were identified retrospectively by using the International Classification of Disease, 10th revision (ICD-10) codes between January 2011 and July 2014. A total of 210 patients with other diseases causing high CRP levels were excluded from the study as follows: 4 patients with connective tissue diseases, 14 patients with respiratory tract or pulmonary infections, 11 patients with genitourinary tract infections, 4 patients with inflammatory bowel disease, 4 patients with soft tissue infections, 3 patients recently underwent any surgical procedure, 2 patients with history of recent burns or trauma, 20 patients with chronic liver disease, 33 patients with malignancy, 108 patients accompanying pancreatitis or cholangitis, and 7 patients younger than 18 years (Figure 1 ).

Demographics, history, physical examination, laboratory, and imaging findings during admission of 682 patients were evaluated, retrospectively. Clinical variables consisting of laboratory and imaging findings were obtained during diagnosis at the time of the admission to hospital, and included in the study. The criteria of Tokyo guidelines were used in grading the severity of acute cholecystitis, and patients were accordingly divided into 3 groups. Group 1 included the patients with grade 1 mild acute cholecystitis, while group 2 included grade 2 moderate acute cholecystitis, and group 3 comprised grade 3 severe cases (Table 1) (3). CRP values at the time of admission were analyzed and compared among the groups. They were studied using Beckman Coulter IMMAGE 800 device with the scale of $\mathrm{mg} / \mathrm{L}$. The reference range was considered as $0.00-5.00$ $\mathrm{mg} / \mathrm{L}$. Other laboratory parameters were studied with Beckman Coulter ACT DIFF 18 models analyzer.

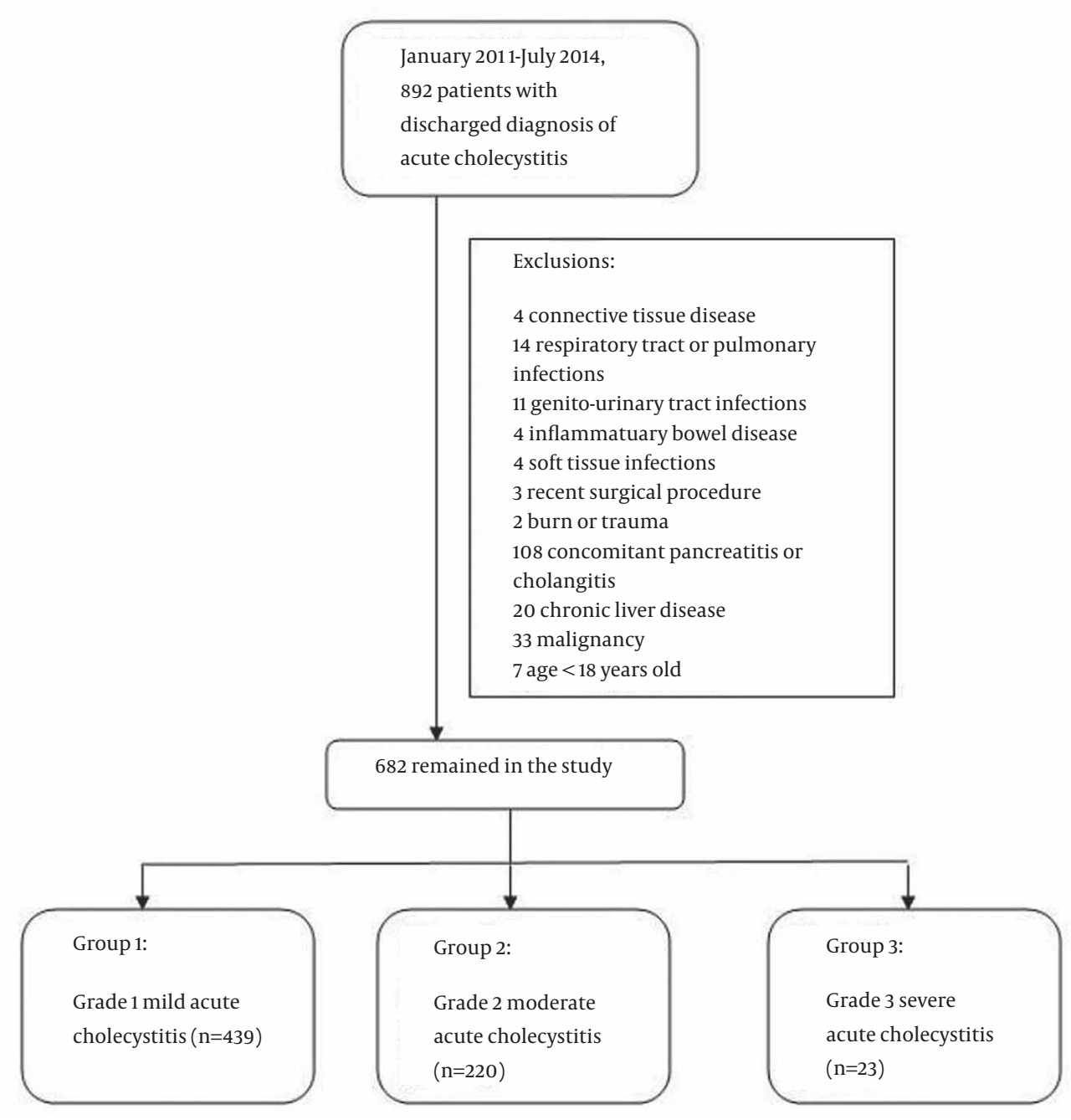

Figure 1. The Flow Chart of Patient's Inclusion Criteria and Groups 
Table 1. Severity Grading According to the Tokyo Guidelines for Acute Cholecystitis ${ }^{\text {a }}$

\begin{tabular}{l|c|}
\hline Grade & Criteria \\
\hline $\mathbf{1}$ & Mild \\
\hline $\mathbf{2}$ & $\begin{array}{c}\text { Acute cholecystitis not meeting other severity criteria. } \\
\text { Mild gallbladder inflammation, no organ dysfunction. } \\
\text { Moderate }\end{array}$ \\
\hline & Acute cholecystitis with any of following conditions: \\
& Elevated WBC count (>18000/mL) \\
\hline & Palpable tender mass at right upper quadrant \\
Darked local inflammation, such as biliary peritonitis, \\
pericholecystic abscess, hepatic abscess, gangrenous \\
cholecystitis, emphysematous cholecystitis
\end{tabular}

3 Severe

Acute cholecystitis is associated with dysfunction of any one of the following organs/systems:

Cardiovascular dysfunction (hypotension requiring treatment with dopamine $>5 \mathrm{mg} / \mathrm{kg} / \mathrm{min}$ (body weight) or any dose of norepinephrine)

Neurological dysfunction (decreased level of consciousness)

Respiratory dysfunction $(\mathrm{PaO} 2 / \mathrm{FiO} 2<300)$

Renal dysfunction (oliguria, creatinine $>2.0 \mathrm{mg} / \mathrm{dL}$ )

Hepatic dysfunction (PT-INR $>1.5$ )

Hematologic dysfunction (platelet count $<100000 / \mathrm{mL}$ )

a Abbreviations: PT-INR: prothrombin time-international normalized ratio; and WBC: white blood cell.

\subsection{Statistical Analysis}

Data were analyzed by using the statistical package for social sciences (SPSS, Chicago IL, USA, 2012). Variation of CRP levels among study groups was analyzed with Kruskal-Wallis test. Spearman correlation test was used for variables with non-normal distribution. The significant cut-off levels of CRP of groups were evaluated with ROC curve analysis, to find out any significance related to the severity of the disease. Sensitivity and specificity for CRP levels were included in ROC data analysis, and Youden's index was calculated for groups 2 and 3. Results were evaluated with 95\% confidence interval, and P values under 0.05 were considered to be statistically significant.

\section{Results}

Out of total participants, 415 patients were female, and 267 were male, with a mean age \pm SD of $51.61 \pm 16.65$ years and median age of 51 years (18 - 93). Following grading of the patients according to Tokyo guidelines, 439 patients were classified into group I with grade 1 cholecystitis, 220 patients into group II with grade 2 cholecystitis, and 23 patients had grade III disease that put them into group 3. Time of the onset of symptoms of a patient was evaluat- ed in grading, according to the guideline. In 682 patients, the minimum time duration interval onset of symptoms and hospital admission was 20 hours, while the maximum interval was 190 hours.

The mean, median, and interquartile range of age in group I was found to be $48.97 \pm 15.47,48$, and $71 \mathrm{y}(18-89)$, respectively. In the same group the mean, median, and interquartile range CRP value of $18.96 \pm 22.20,10.2$, and $19 \mathrm{mg} / \mathrm{L}$ (0.10 - 128.2), respectively. The mean duration between the onset of symptoms and hospital admission was 50.2 hours (20 - 65).

The mean, median, and interquartile age range of patients in group II were 55.06 \pm 17.51, 56 and 75 y (18 - 93), respectively. In the same group the mean, median, and interquartile range of CRP values were 133.51 \pm 76.55, 135.2 and $120.9 \mathrm{mg} / \mathrm{L}$ (9.20 - 280.70). Those patients were considered as grade 2 , because pure leukocytosis ( $>18.000 /$ $\mathrm{mm}^{3}$ ) was found in 71, perforation of the gallbladder in 12 , gangrenous gallbladder in 15 , with symptoms lasting longer than 72 hours in 125 cases, including 15 cases with gangrenous cholecystitis and 12 with perforation of the gallbladder, as well as finding a palpable mass in the right upper quadrant in 24 patients. The mean duration between the onset of symptoms and admission was found to be 108.7 hours ( 36 - 190), of them 56.8\% (125 patients) had a longer time than 72 hours.

Twenty-three patients were entered later into group III from group II, because of having at least one organ insufficiency found during medical treatment or follow-up. Eleven of those patients developed oliguria and or increase in creatinine levels $>2 \mathrm{mg} / \mathrm{dL}$ during follow-up. Mean age of those patients with renal insufficiency was 56.7 y (39-67), and none of them had a previous renal disease or used any nephrotoxic agent. Following intravenous fluid therapy, renal functions came back to normal in all of them.

An 89-year-old patient that had referred to the hospital with symptoms lasting longer than 96 hours had an onset of hallucinations and mental confusion. No intracranial pathology was observed and serum electrolyte levels were in normal ranges. After neurological and psychiatric evaluations, it was differentiated as a delirium state, triggered by acute cholecystitis.

In 3 patients, with a mean age of $58.3 \mathrm{y}(45-72)$, platelet levels were decreased to $84000 / \mathrm{mm}^{3}, 92000 / \mathrm{mm}^{3}$, and $95000 / \mathrm{mm}^{3}$ and they stayed at those levels during follow-up. None of them had a history of a hematologic disorder. We did not observe any bleeding due to thrombocytopenia in those patients, and the levels came back spontaneously to normal ranges following treatment of acute cholecystitis.

In 8 patients, without any history of using anticoagulant agents, international normalized ratio (INR) levels were found to be increased to a mean level of 1.68 (1.50 -1.98). In 6 of them, aspartate transaninase (AST) and alanine transaminase (ALT) levels with 3-10 times of normal values were also observed with high INR levels. The mean 
age of those 6 patients that were considered to have hepatic dysfunction was $62.4 \mathrm{y}(40-87)$ and hepatic failure did not develop in any of them.

In group III, CRP levels before emergent surgical procedures towards gallbladder were evaluated. Mean, median, and interquartile range of CRP level in group III was found to be $237.23 \pm 62.56,250.7$, and $218.5 \mathrm{mg} / \mathrm{L}$ (117.1 - 335.6), respectively. Their mean, median and interquartile range age were $68.78 \pm 14.28,72$ and 50 y (39-89), respectively. CRP levels in 121 patients were within normal limits, and all of these patients were in group I with grade 1 acute cholecystitis. Both group II and group III did not include any patient with normal CRP levels. Clinical characteristics of patients were summarized in Table 2 .

When CRP values were examined among the groups, mean and median CRP levels in each group were found to be significantly different $(\mathrm{P}<0.0001)$.

In addition, they were found to be highly correlated with the disease grade, and these correlations are statistically significant and moderately positive $(\mathrm{P}<0.001, \mathrm{r}=0.743)$ (Table 3). After evaluating CRP levels according to the disease grade, for group II the AUC (area under the curve) was $93.8 \%$, which was very high. LR+ (likelihood ratio) value is 268. As the area under the curve for group II is high, LR+ value is strong, the sensitivity of CRP test is $75.5 \%$, (moderate) and the specificity is $96.6 \%$, (strong) for determining the grade 2 acute cholecystitis. For group III, the AUC is $84.6 \%$, which is also very high. $L R+$ value is 87 . As the area under the curve for group III is high, $\mathrm{LR}+$ value is strong, with the sensitivity of $73.9 \%$ and the specificity of $75.5 \%$, (moderate) for determining the grade 3 acute cholecystitis (Figure 2). Those results were found to be statistically significant $(\mathrm{P}<$ $0.0001)$. Youden's index was found to be 0.72 for group II and 0.49 for group III (Table 4 ). As a result, although cut-off values of CRP levels for both groups (groups II and III) have a diagnostic power; they are more meaningful for group II than group III to determine the grade of acute cholecystitis using CRP levels.

\begin{tabular}{|c|c|c|c|}
\hline Groups & $\begin{array}{c}\text { Group I (Grade } 1 \\
\text { Acute Cholecystitis) } \\
(\mathbf{n}=439)\end{array}$ & $\begin{array}{c}\text { Group II (Grade } 2 \\
\text { Acute Cholecystitis) } \\
(\mathbf{n = 2 2 0})\end{array}$ & $\begin{array}{l}\text { Group III (Grade } 3 \\
\text { acute Cholecystitis) } \\
\qquad(\mathbf{n}=23)\end{array}$ \\
\hline \multicolumn{4}{|l|}{ Demographic data of the groups } \\
\hline Mean Age & 48.97 & 55.06 & 68.78 \\
\hline Median Age & 48 & 56 & 72 \\
\hline \multicolumn{4}{|l|}{ Gender } \\
\hline Male & 169 & 87 & 9 \\
\hline Female & 270 & 133 & 14 \\
\hline Mean duration of symptoms, $\mathrm{h}$ & 50.2 & 108.7 & - \\
\hline \multicolumn{4}{|l|}{ Characteristics of groups by diagnostic criteria } \\
\hline Murphy's sign & 138 & 70 & 8 \\
\hline RUQ mass/pain/tenderness & 301 & 150 & 15 \\
\hline Fever & 28 & 35 & 19 \\
\hline Elevated CRP & 318 & 220 & 23 \\
\hline Elevated WBC count & 72 & 142 & 21 \\
\hline Imaging findings & 439 & 220 & 23 \\
\hline \multicolumn{4}{|l|}{ Characteristics of groups by severity grade } \\
\hline Palpable tender mass in the right upper abdominal quadrant & - & 24 & - \\
\hline Elevated WBC count, $>18000 / \mathrm{mm}^{3}$ & - & 98 & 17 \\
\hline Duration of complaints $>72$ hours & - & 125 & 9 \\
\hline Marked local inflammation & - & 27 & - \\
\hline Cardiovascular dysfunction & - & - & - \\
\hline Neurological dysfunction & - & - & 1 \\
\hline Respiratory dysfunction & - & - & - \\
\hline Renal dysfunction & - & - & 11 \\
\hline Hepatic dysfunction & - & - & 8 \\
\hline Hematological dysfunction & - & - & 3 \\
\hline
\end{tabular}

\footnotetext{
${ }^{\mathrm{a}}$ Abbreviations: RUQ, Right upper quadrant; WBC, White blood cell.
} 
A

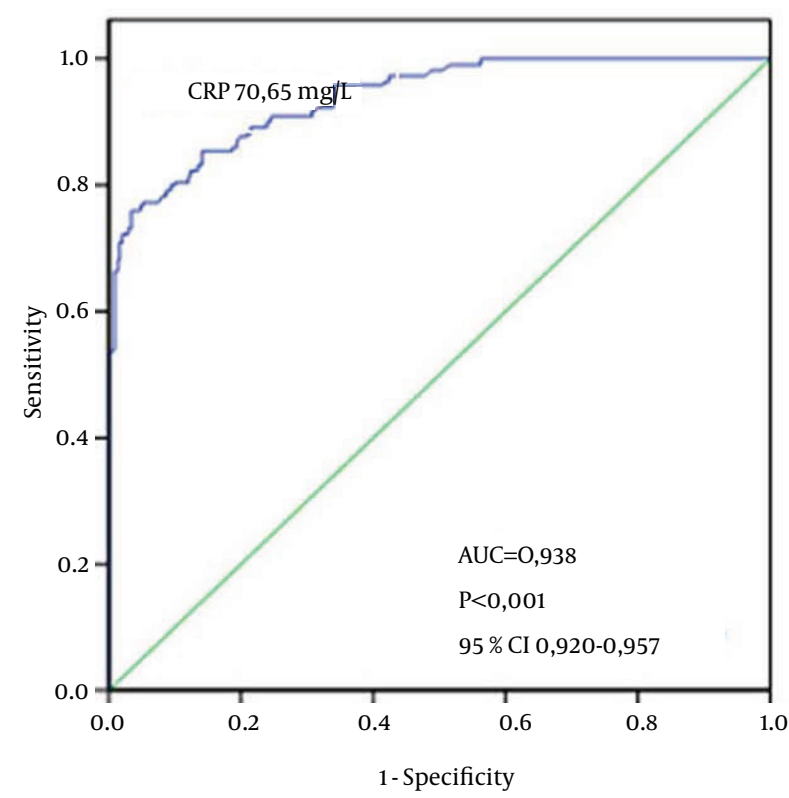

B

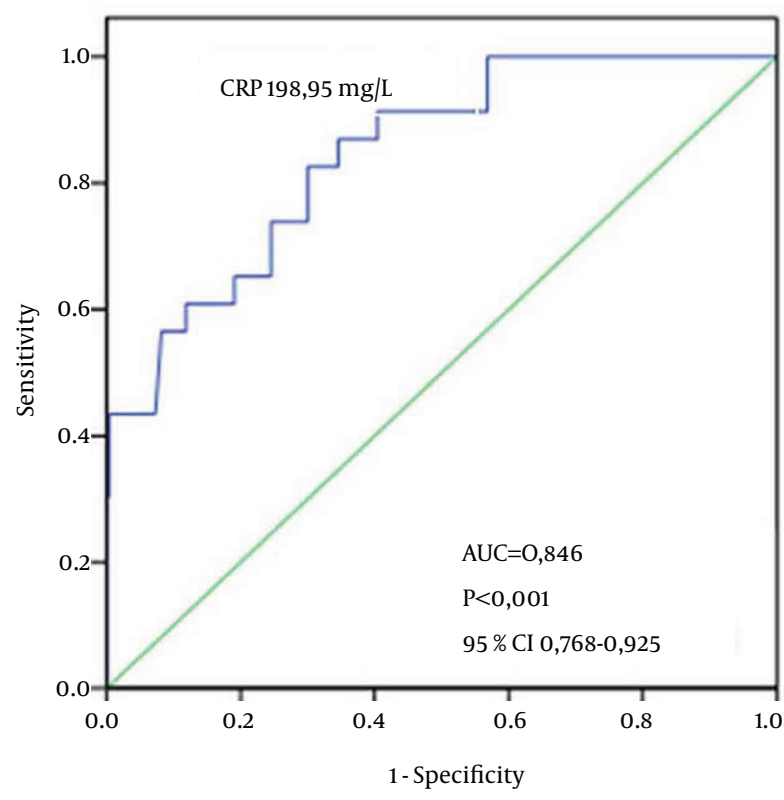

AUC, area under the curve; CI, confidence interval.

Table 3. Correlations between the groups (grade) and CRP measurements ${ }^{\mathrm{a}}$

\begin{tabular}{lcc}
\hline & \multicolumn{2}{c}{ CRP at admission, $\mathbf{~ m g / L}$} \\
\hline Group & $\mathrm{r}$ & P Value \\
& 0.743 & 0.001 \\
\hline
\end{tabular}

${ }^{a}$ Abbreviation: r, correlation coefficient.

Table 4. Comparison of Cut-Off values of CRP Indicating the Separation of the Groups ${ }^{\text {a }}$

\begin{tabular}{lcc}
\hline & Group II & Group III \\
\hline CRP cut-off value, mg/L & 70.65 & 198.95 \\
Sensitivity, \% & 75.5 & 73.9 \\
Specificity, \% & 96.5 & 75.5 \\
PPV & 91.7 & 75.8 \\
NPV & 88.9 & 96.5 \\
Youden's index & 0.72 & 0.49 \\
\hline
\end{tabular}

${ }^{\mathrm{a}}$ Abbreviations: $\mathrm{PPV}$, positive predictive value; NPV, negative predictive value.

According to the predictive values in our series, level of CRP seems to differentiate cases from each other in terms of the severity of the disease as defined in Tokyo guidelines. Following hospital admission, patients with CRP level $>70.65 \mathrm{mg} / \mathrm{L}$ may be considered as grade 2 acute cholecystitis, while patients with CRP level $>198.95 \mathrm{mg} / \mathrm{L}$ may be considered as grade 3 cholecystitis, and medical treatment can be planned accordingly.

\section{Discussion}

Cholecystitis is a syndrome that entails a continuation of clinicopathologic states (14); one end of this continuum is acute cholecystitis (15). Developed in 2007 and revised in 2013, Tokyo guidelines standardized the diagnosis and treatment of acute cholecystitis for the first time $(4,5)$. In this guideline, the disease is diagnosed and its severity is graded based on clinical, laboratory and imaging results (Table 1). It proposes a management strategy for the disease following the assessment of its severity. Tokyo guidelines recommend early laparoscopic cholecystectomy for grade 1 acute cholecystitis and elective cholecystectomy for grade 2 patients as the first-line of treatment. If a patient with grade 2 acute cholecystitis does not respond to initial medical treatment, urgent, or early gallbladder drainage is required. For patients with grade 3 acute cholecystitis, urgent or early gallbladder drainage is essential in addition to organ support and medical treatment $(5,16)$.

According to Tokyo guidelines, CRP, a well-known acute phase reactant that increases rapidly in inflammatory processes, is included in the laboratory findings for the diagnosis of acute cholecystitis. In various studies, CRP has been found to be a strong predictive factor in determining the severity of gallbladder inflammation (17-19). In patients of acute cholecystitis with high levels of CRP, conversion from laparoscopic to open procedure was found to be at higher rates (12, 20-24). However, unlike while blood cell count that has taken place in grading the disease according to the guideline, the predictive value of 
CRP has not been determined and accepted among prognostic factors yet.

Proceeding from this point, in our study, we aimed to observe whether this well-known inflammatory marker has a predictive cut-off level for the severity of the disease, i.e., be one of the decision keys before the onset of the treatment. According to our results, different grades of the disease can be distinguished from each other, based on different CRP levels.

In previous studies, regarding the grading of the disease according to Tokyo guidelines, no cut-off values of CRP have been proposed so far. However, in a study by Nikfarjam et al., CRP value $>94 \mathrm{mg} / \mathrm{L}$ was found to be a significant risk factor for gangrenous cholecystitis (19). Similarly, Asai et al. reported a significant correlation between high risk of bactobilia and advanced age, high levels of CRP, and the evidence of significant gallbladder infection. In their study, the cut-off CRP value was found to be $134 \mathrm{mg} / \mathrm{L}$ for bactobilia (22).

In general, levels of CRP of up to $10 \mathrm{mg} / \mathrm{L}$ are considered clinically insignificant for acute inflammatory reactions. On the other hand, CRP levels of $100 \mathrm{mg} / \mathrm{L}$ or more are strongly associated with local tissue necrosis (22-26). In a study that observed CRP levels in the diagnosis of sepsis, the threshold value was considered to be $>100 \mathrm{mg} / \mathrm{L}$, but no cut-off value was defined (27).

In our study, patients with grade 2 acute cholecystitis were found to be statistically different than grade 1 at CRP level of $70.65 \mathrm{mg} / \mathrm{L}$ or above, while patients with CRP levels of $198.95 \mathrm{mg} / \mathrm{L}$ or above were found to be correlated with grade 3 diseases.

According to Tokyo guidelines, grade 1 patients are cases with uncomplicated acute cholecystitis. These patients constitute the group without bacteremia or sepsis. Therefore, very high CRP levels are not usually encountered in patients with grade 1 acute cholecystitis. It is even possible to see patients with normal CRP levels, such as some of the patients in group $1(n=121)$ of our study. We found mean CRP levels of $18.96 \mathrm{mg} / \mathrm{L}$ in grade 1 disease, and cut-off value for grade 2 was determined to be 70.65 $\mathrm{mg} / \mathrm{L}$, with a specificity of $96.6 \%$. This level is under the threshold that points tissue necrosis and gangrene in the literature and seems to be compatible with cases of grade 1 acute cholecystitis.

Unlike the cases with grade 1, gallbladder inflammation in grade 2 patients gets complicated, and may be accompanied by bacteremia, systemic inflammatory response syndrome (SIRS) or sepsis, but not organ dysfunction. Thus, CRP is expected to be at higher levels in this group. In our study, we found CRP levels as high as $133.51 \mathrm{mg} / \mathrm{L}$ in group II, significantly higher than group I. However, assuming CRP cut-off value of $70.65 \mathrm{mg} / \mathrm{L}$ distinguishes grade 2 from grade 1 ; this value may be considered to be under CRP values, indicating tissue necrosis and gangrene as reported in the literature. Nevertheless in our study, CRP cut-off value of $198.95 \mathrm{mg} / \mathrm{L}$ differentiated grade 3 disease from grade 2 disease. Accordingly, pa- tients with CRP levels up to $198.95 \mathrm{mg} / \mathrm{L}$ can be assumed as grade 2 disease.

Based on Tokyo guideline, patients with grade 3 cholecystitis have accompanying organ dysfunction, but it was not emphasized in the first guideline whether it was evident at the time of admission or diagnosed during follow-up $(4,5)$. Cheng et al. pointed out that patients who have comorbidity, but are not complicated with organ dysfunction on admission, will be graded as 1 or 2 (28). Later, Yokoe et al. determined organ dysfunction as the proceeding of acute cholecystitis from mild/moderate forms into severe (29). In our study, 23 patients receiving medical treatment developed organ dysfunction during the course of the disease, so they were included into grade 3 disease. Those patients had been classified as cases with grade 2 disease at the time of the admission, but following failure of medical therapy, they were ended up with sepsis and/or organ dysfunction. Later they were treated with gallbladder drainage or cholecystectomy, resulting in dramatic recovery. The rate of mortality was $0 \%$ in all groups.

In our study, mean CRP level of grade 3 patients before any surgical procedure was found to be as high as 237.23 $\mathrm{mg} / \mathrm{L}$, which seems to be consistent with the main idea of the study. Although the severity of local inflammation is proportional to the increase in CRP levels, some studies report no significant difference between non-infectious SIRS, sepsis, and organ dysfunction in terms of CRP levels (30-34). We found the cut-off values of CRP as 198.95 $\mathrm{mg} / \mathrm{L}$ with a sensitivity of $75.5 \%$, in patients with grade 3 disease.

One of the weaknesses of our study is its retrospective nature. However, up to the present, we did not found any similar study analyzing levels of CRP at different cut-off values to predict the grade of the acute cholecystitis. Besides, our study has a larger number of cases compared to many previous studies on acute cholecystitis. On the other hand, number of patients with grade 3 acute cholecystitis in this study could be considered as quite low. However, according to the studies that have evaluated Tokyo guideline, grade 3 acute cholecystitis has been reported to evolve out of $1.2 \%$ - $6 \%$ of all cases $(5,22,27,29)$. In our study, this rate was found to be $3.3 \%$, similar to these results.

When the diagnosis of acute cholecystitis is determined based on the criteria of Tokyo guidelines, severity of the disease should be assessed initially, to set up the management strategy. According to our results, CRP level can be a predictor in classifying different grades of the disease. However, further studies are needed to describe the exact role of CRP level in grading acute cholecystitis.

\section{References}

1. Strasberg SM. Clinical practice. Acute calculous cholecystitis. $N$ Engl J Med. 2008;358(26):2804-11.

2. Okamoto K, Takada T, Strasberg SM, Solomkin JS, Pitt HA, Garden OJ, et al. TG13 management bundles for acute cholangitis and 
cholecystitis. J Hepatobiliary Pancreat Sci. 2013;20(1):55-9.

3. Mayumi T, Someya K, Ootubo H, Takama T, Kido T, Kamezaki F, et al. Progression of Tokyo Guidelines and Japanese Guidelines for management of acute cholangitis and cholecystitis. J UOEH. 2013;35(4):249-57.

4. Hirota M, Takada T, Kawarada Y, Nimura Y, Miura F, Hirata K, et al. Diagnostic criteria and severity assessment of acute cholecystitis: Tokyo Guidelines. J Hepatobiliary Pancreat Surg. 2007;14(1):7882.

5. Yokoe M, Takada T, Strasberg SM, Solomkin JS, Mayumi T, Gomi $\mathrm{H}$, et al. New diagnostic criteria and severity assessment of acute cholecystitis in revised Tokyo Guidelines. J Hepatobiliary Pancreat Sci. 2012;19(5):578-85.

6. Vigushin DM, Pepys MB, Hawkins PN. Metabolic and scintigraphic studies of radioiodinated human C-reactive protein in health and disease. J Clin Invest. 1993;91(4):1351-7.

7. Andersson RE, Hugander AP, Ghazi SH, Ravn H, Offenbartl SK, Nystrom PO, et al. Diagnostic value of disease history, clinical presentation, and inflammatory parameters of appendicitis. World J Surg. 1999;23(2):133-40.

8. Gronroos JM, Gronroos P. Leucocyte count and C-reactive protein in the diagnosis of acute appendicitis. BrJ Surg. 1999;86(4):501-4.

9. Adamian AI, Guliaev AA, Ivanina TA, Evteeva EA, Samsonov VT. [Acute phase response and plasma proteins in acute cholecystitis]. Klin Lab Diagn. 1997(11):8-10.

10. Sekimoto M, Imanaka Y, Hirose M, Ishizaki T, Murakami G, Fukata $\mathrm{Y}$, et al. Impact of treatment policies on patient outcomes and resource utilization in acute cholecystitis in Japanese hospitals. BMC Health Serv Res. 2006;6:40.

11. Aydin C, Altaca G, Berber I, Tekin K, Kara M, Titiz I. Prognostic parameters for the prediction of acute gangrenous cholecystitis. $J$ Hepatobiliary Pancreat Surg. 2006;13(2):155-9.

12. Wevers KP, van Westreenen HL, Patijn GA. Laparoscopic cholecystectomy in acute cholecystitis: C-reactive protein level combined with age predicts conversion. Surg Laparosc Endosc Percutan Tech. 2013;23(2):163-6.

13. Mok KW, Reddy R, Wood F, Turner P, Ward JB, Pursnani KG, et al. Is C-reactive protein a useful adjunct in selecting patients for emergency cholecystectomy by predicting severe/gangrenous cholecystitis? Int J Surg. 2014;12(7):649-53.

14. Indar AA. Acute cholecystitis. Bmj. 2002;325(7365):639-43.

15. Cho JY, Han HS, Yoon YS, Ahn KS. Risk factors for acute cholecystitis and a complicated clinical course in patients with symptomatic cholelithiasis. Arch Surg. 2010;145(4):329-33.

16. Miura F, Takada T, Strasberg SM, Solomkin JS, Pitt HA, Gouma DJ, et al. TG13 flowchart for the management of acute cholangitis and cholecystitis. J Hepatobiliary Pancreat Sci. 2013;20(1):47-54.

17. Juvonen T, Kiviniemi H, Niemela O, Kairaluoma MI. Diagnostic accuracy of ultrasonography and $\mathrm{C}$ reactive protein concentration in acute cholecystitis: a prospective clinical study. Eur J Surg. 1992;158(6-7):365-9.

18. Durai R, Cheng X, Fernandes C, Razvi A, Ng PC. 'Lewisham scoring system' to facilitate the clinical diagnosis of empyema. Acta Chir Belg. 2010;110(6):590-4.
19. Nikfarjam M, Niumsawatt V, Sethu A, Fink MA, Muralidharan V Starkey G, et al. Outcomes of contemporary management of gangrenous and non-gangrenous acute cholecystitis. HPB (Oxford). 2011;13(8):551-8.

20. Schafer M, Krahenbuhl L, Buchler MW. Predictive factors for the type of surgery in acute cholecystitis. Am J Surg. 2001;182(3):291-7.

21. Teckchandani N, Garg PK, Hadke NS, Jain SK, Kant R, Mandal AK et al. Predictive factors for successful early laparoscopic cholecystectomy in acute cholecystitis: a prospective study. Int J Surg. 2010;8(8):623-7.

22. Asai K, Watanabe M, Kusachi S, Tanaka H, Matsukiyo H, Osawa A, et al. Bacteriological analysis of bile in acute cholecystitis according to the Tokyo guidelines. J Hepatobiliary Pancreat Sci. 2012;19(4):476-86.

23. Licciardello A, Arena M, Nicosia A, Di Stefano B, Cali G, Arena G et al. Preoperative risk factors for conversion from laparoscopic to open cholecystectomy. Eur Rev Med Pharmacol Sci. 2014;18(2 Suppl):60-8.

24. Borzellino G, Sauerland S, Minicozzi AM, Verlato G, Di Pietrantonj C, de Manzoni G, et al. Laparoscopic cholecystectomy for severe acute cholecystitis. A meta-analysis of results. Surg Endosc. 2008;22(1):8-15.

25. Gabay C, Kushner I. Acute-phase proteins and other systemic responses to inflammation. N Engl J Med.1999;340(6):448-54.

26. Zimmerman MA, Selzman $\mathrm{CH}$, Cothren C, Sorensen AC, Raeburn CD, Harken AH. Diagnostic implications of C-reactive protein. Arch Surg. 2003;138(2):220-4

27. Simon L, Gauvin F, Amre DK, Saint-Louis P, Lacroix J. Serum procalcitonin and C-reactive protein levels as markers of bacterial infection: a systematic review and meta-analysis. Clin Infect Dis. 2004;39(2):206-17.

28. Cheng WC, Chiu YC, Chuang CH, Chen CY. Assessing clinical outcomes of patients with acute calculous cholecystitis in addition to the Tokyo grading: a retrospective study. Kaohsiung J Med Sci. 2014;30(9):459-65.

29. Yokoe M, Takada T, Strasberg SM, Solomkin JS, Mayumi T, Gomi H, et al. TG13 diagnostic criteria and severity grading of acute cholecystitis (with videos). J Hepatobiliary Pancreat Sci. 2013;20(1):35-46.

30. Kimura Y, Takada T, Strasberg SM, Pitt HA, Gouma DJ, Garden OJ, et al. TG13 current terminology, etiology, and epidemiology of acute cholangitis and cholecystitis. J Hepatobiliary Pancreat Sci. 2013;20(1):8-23.

31. Lee SW, Yang SS, Chang CS, Yeh HJ. Impact of the Tokyo guidelines on the management of patients with acute calculous cholecystitis. J Gastroenterol Hepatol. 2009;24(12):1857-61.

32. Morley JJ, Kushner I. Serum C-reactive protein levels in disease. Ann N Y Acad Sci.1982;389:406-18.

33. Mitaka C. Clinical laboratory differentiation of infectious versus non-infectious systemic inflammatory response syndrome. Clin Chim Acta. 2005;351(1-2):17-29.

34. Brunkhorst FM, Wegscheider K, Forycki ZF, Brunkhorst R. Procalcitonin for early diagnosis and differentiation of SIRS, sepsis, severe sepsis, and septic shock. Intensive Care Med. 2000;26 Suppl 2:S148-52. 